\title{
In situ TEM oxidation study of Fe thin-film transformation to single-crystal magnetite nanoparticles
}

\author{
${\text { Leonardo } \text { Lari }^{1,2, *} \text { (D), Stephan Steinhauer }}^{3}$ (D), and Vlado K. Lazarov ${ }^{1,2}$ (1) \\ ${ }^{1}$ Physics Department, University of York, Heslington, York YO10 5DD, UK \\ ${ }^{2}$ The York-JEOL Nanocentre, Helix House, Science Park, Heslington, York YO10 5BR, UK \\ ${ }^{3}$ Nanoparticles by Design Unit, Okinawa Institute of Science and Technology (OIST) Graduate University, 1919-1 Tancha Onna-Son, \\ Okinawa 904-0495, Japan
}

Received: 5 March 2020

Accepted: 4 June 2020

Published online:

16 June 2020

(C) The Author(s) 2020

\begin{abstract}
In this work, we present an in situ transmission electron microscopy (TEM) study of Fe thin films to Fe nanoparticle formation and their oxidation to singlecrystal magnetite nanoparticles. Amorphous Fe thin films were prepared by sputtering on TEM carbon grids. The thin Fe films were continuously heated in situ from room temperature to $700{ }^{\circ} \mathrm{C}$ under vacuum $\left(4 \times 10^{-4} \mathrm{~Pa}\right)$. With the increase in temperature, the continuity of the thin film starts breaking, and $\mathrm{Fe}$ nanoparticle nucleation centers are formed. At $600{ }^{\circ} \mathrm{C}$, the thin film transforms into metallic Fe nanoparticles (NPs) with a small presence of different Fe oxide NPs. Further increase in the temperature to $700{ }^{\circ} \mathrm{C}$ resulted in the full oxidation of the NPs (i.e., no core-shell were found). Zero-loss energy filtered diffraction and HRTEM analysis of the lattice spacing reveals that all NPs have fully transformed into single-phase magnetite NPs. The structural study of the magnetite NPs shows that magnetite NPs are free of antiphase domain boundary defects. This work demonstrates that under low partial pressure of oxygen at elevated temperatures a complete oxidation of Fe NPs into magnetite single-crystal nanoparticles can be achieved.
\end{abstract}

\section{Introduction}

The study of iron oxide nanoparticles (NPs) has burgeoned during the last decades [1-3] due to their range of applications that include water purification [4], ferrofluids [5], hyperthermia treatments of tumors [6], chemical sensing [7, 8], magnetic resonance imaging contrast enhancement agents [9], and catalyst support [10-12].

There are both chemical [13-17] and physical methods to produce iron oxide NPs [16, 18]. Physical methods include post-growth oxidation of sputtered Fe NPs [19, 20] and laser-induced pyrolysis [21]. Independently from the preparation methods,

Address correspondence to E-mail: leonardo.lari@york.ac.uk 
obtaining iron oxides NPs with bulk-like structures has been shown to be very challenging, e.g., core/ shell structures $\mathrm{Fe} / \mathrm{Fe}$-oxides are a common outcome $[19,20,22]$ as well as the presence of antiphase boundaries [23]. Such type of defects, commonly occurring in thin Fe oxide films [24, 25], are known to reduce the magnetization of the material [23], detrimental to some of their applications. Although methods for the production on large scale of freestanding iron oxide NPs are important, the fundamental understanding of iron crystals formation and evolution under controlled gas and temperature is a key for the development of potential industrial applications. In this work, we demonstrate that annealing in low $\mathrm{O}_{2}$ pressure of pre-sputtered iron thin films results in single-crystal $\mathrm{Fe}_{3} \mathrm{O}_{4}$ (magnetite) NP formation. By performing in situ TEM studies, we were able to characterize the structural phase transformations from thin Fe film to single-crystal magnetite NPs.

Historically ample literature has been produced on the oxidation mechanism of iron and phase transformations of iron oxides from bulk materials to thin films down to nanoparticles [16, 17, 26-31]. Phase diagrams for the $\mathrm{Fe}-\mathrm{O}$ system in bulk materials are well known [32], but they are not directly applicable to nanoscale objects. In situ heating and gas environmental electron microscopy [33] provide unique opportunities to investigate the oxidation down to the nanometer and atomic scale in quasi-equilibrium conditions. One of the challenges present during this type of studies is the effect of the electron beam and the residual gas molecules in the microscope column [34] on the oxidation dynamics [35], hence the final product of the oxidation. In this work, we utilize the residual $\mathrm{O}_{2}$ in the microscope column to perform low-pressure $\left(4.0 \times 10^{-4} \mathrm{~Pa}\right)$ oxidation study during in situ heating of iron sputtered thin films as a function of temperature. To avoid phase transformations driven by the electron beam, heating of the sample was done with the beam off, and the TEM imaging was performed for very short time (in order of seconds) by continuously changing area of observation. Due to the close lattice spacing of the iron oxide phases of interest $\left(\mathrm{Fe}_{3} \mathrm{O}_{4}\right.$ and $\left.\gamma-\mathrm{Fe}_{2} \mathrm{O}_{3}\right)$, standard TEM imaging techniques are not able to distinguish between these two phases; here we show that energy filtered electron diffraction can overcome such a limitation.

\section{Materials and methods}

Samples for TEM investigation were deposited directly on amorphous holey carbon films supported by TEM Cu grids (AGAR Holey Carbon Films on 200 Mesh Copper Grids, AGS147) by glow discharge sputter coating. The holy carbon support film has a nominal thickness of 10-15 nm; such a thickness has been chosen as a compromise between ultrathin carbon films $(3 \mathrm{~nm})$ and standard carbon film (28-30 nm), in order to ensure robustness during the heating experiment in the presence of residual gas. The TEM grids were put centrally in the bottom of the vacuum chamber of a high-resolution plasma sputter coater (model JFC-2300HR, JEOL Ltd) with the carbon film facing up toward an iron target (SuperVac ${ }^{\circledR}$ Fe target $99.9 \%$ purity, $0.1 \mathrm{~mm}$ thickness, Testbourne Ltd). Sputtering was performed for $60 \mathrm{~s}$ at a current setting of $40 \mathrm{~mA}$ using gas argon (99.999\% Zero Grade Argon, BOC); the deposited film thickness, as measured by the quartz monitor of the sputter coater, was below $1 \mathrm{~nm}$.

In situ electron microscopy was performed using an environmental transmission electron microscope (TEM) operating at $300 \mathrm{kV}$ (Titan, FEI) and equipped with a third-order image aberration corrector (Cetcor, CEOS). Samples were loaded on a single tilt heating holder (Gatan, model 628). Sample temperature was controlled and monitored by using a SmartSet hot stage controller (Gatan, model 901).

\section{Results and discussion}

The as-sputtered thin film supported by the carbon film was transferred in air and loaded to the TEM microscope column with a vacuum basic pressure of $4.0 \times 10^{-4} \mathrm{~Pa}$, as measured by the microscope column vacuum gauge, corresponding to a residual oxygen partial pressure of $0.8 \times 10^{-4} \mathrm{~Pa}$ (calculated assuming a $21 \%$ Oxygen fraction as in the atmosphere). As shown in Fig. 1, both HRTEM images (Fig. 1a) and electron diffraction patterns (Fig. 1b) do not reveal any atomic ordering (no atomic fringes in HRTEM) neither clear sharp diffraction rings.

The temperature was then ramped up to $600{ }^{\circ} \mathrm{C}$ from room temperature, with a linear rate in $30 \mathrm{~min}$. Before exposing the sample to the electron beam for imaging, the specimen holder was left to stabilize thermally to reduce drift for additional $60 \mathrm{~min}$. After 
this annealing step, nanoparticles with round shape with an average diameter of $5.2 \mathrm{~nm}$ were formed, as shown in Fig. 2a, b.

Diffraction patterns show that annealing has started the crystallization process, which resulted in crystalline NP formation within the amorphous/ semicrystalline thin film. This is concluded from the simultaneous presence of sharp and diffusive diffraction rings presented in Fig. 2c-e. Detailed analysis of these diffraction rings using JEMS software revealed that the crystalline NPs have spacings mostly corresponding to bulk iron- $\alpha$ phase as shown in Fig. 2c, as well as some diffraction spots and a minor ring compatible with the other major bulk iron oxide phases such as magnetite $\left(\mathrm{Fe}_{3} \mathrm{O}_{4}\right)$ as shown in Fig. $2 d$, hematite $\left(\alpha-\mathrm{Fe}_{2} \mathrm{O}_{3}\right)$, and maghemite $(\gamma-$ $\mathrm{Fe}_{2} \mathrm{O}_{3}$ ). Calculated diffraction patterns for wustite $(\mathrm{FeO})$ and iron carbide $\left(\mathrm{Fe}_{3} \mathrm{C}\right)$ do not fit the experimental data. In fact, in bulk ferrite ( $\alpha$-iron), carbon solubility is as low as $<0.00005 \mathrm{wt} \%$ at room temperature which can increase up to $0.02 \mathrm{wt} \%$, at about $720{ }^{\circ} \mathrm{C}$, where $\mathrm{Fe}$ is supersaturated with $\mathrm{C}$ in the interstitial positions. Quenching the supersaturated $\mathrm{Fe}$ down to the range $20-300{ }^{\circ} \mathrm{C}$ leads to $\mathrm{Fe}_{3} \mathrm{C}$ precipitate formation [36]. In this work, we have not found any evidence (both by HRTEM and electron diffraction) of the $\mathrm{Fe}_{3} \mathrm{C}$ structure at the experimental temperatures used; hence, solubility of C into NPs if present does not result in a distinctive structural phase.

With further increase in the temperature, raised to $700{ }^{\circ} \mathrm{C}$, the film completely dewets from the support and the formation of nanoparticles with increased abundance, size, and pronounced morphology is obtained (Fig. 3). Faceting of the NPs is now evident (Fig. 3a, b) compared to the round nanoparticles obtained at $600{ }^{\circ} \mathrm{C}$ (Fig. 2). We note that crystallinity of the NPs is extending well to their surfaces, in contrast to observed disorder at surfaces in metallic NPs [3]. The drastic phase transformation due to the increase in temperature is also evident from the diffraction patterns taken at $700{ }^{\circ} \mathrm{C}$, as shown in Fig. 3. Diffraction ring analysis (as discussed later in Fig. 5a) confirms atomic planes spacing compatible with both magnetite $\left(\mathrm{Fe}_{3} \mathrm{O}_{4}\right)$ and maghemite $(\gamma-$ $\mathrm{Fe}_{3} \mathrm{O}_{4}$ ), indicating that the low pressure of oxygen in the microscope column is sufficient, at $700{ }^{\circ} \mathrm{C}$, for a full oxidation of the formed nanoparticles. In fact, no evidences of core/shell structures or metallic nanoparticles were found by imaging or electron diffraction.

HRTEM imaging of single nanoparticles show lattice spacings corresponding to orientations of NPs along the major crystallographic axes [111], [100], and [2-1-1], Figure 4. Atomic spacing measurements from the HRTEM images are compatible with both maghemite and magnetite phases.

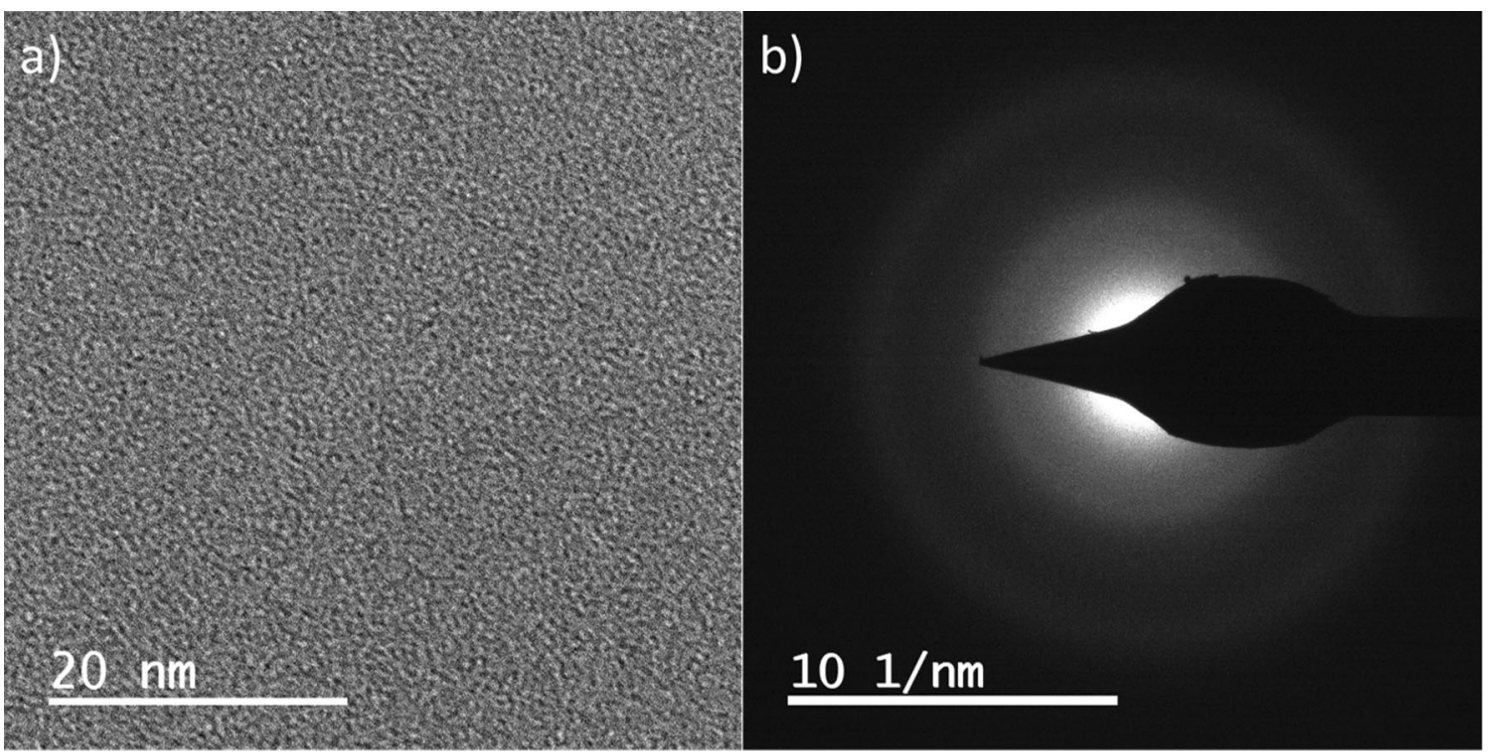

Figure 1 As sputtered Fe thin film before annealing. a Bright field TEM image showing the support and sputtered material; $\mathbf{b}$ diffraction pattern showing diffuse rings typical of amorphous materials. 
Figure 2 Nanoparticle formation at $600{ }^{\circ} \mathrm{C}$. a Bright field image showing nanoparticles formed onto the carbon film support;

b nanoparticle statistic over 141 nanoparticles from several images showing a $5.2 \mathrm{~nm}$ mean NPs diameter (equivalent area circular diameter); diffraction pattern showing rings corresponding to the NP polycrystalline phase; DP analysis shows that the main phase is $\alpha-\mathrm{Fe}(\mathbf{c})$, with extra rings compatible with the main iron oxide phases magnetite (d), hematite (e), and maghemite (not shown here).

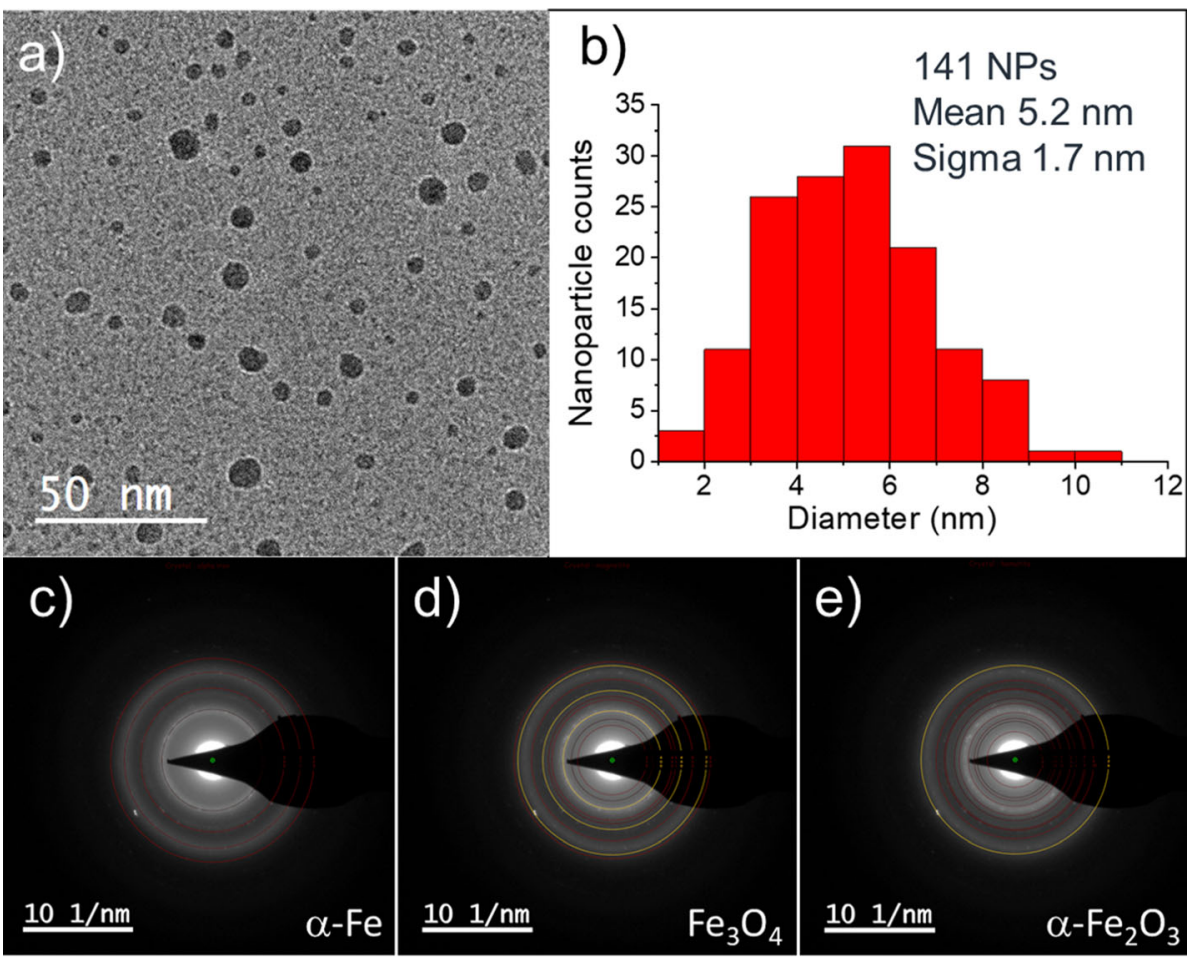

We note that the accuracy of spacing measurements using the HRTEM ( 2\% error) does not allow to distinguish between the maghemite and magnetite NPs, since the difference of their lattice spacings is only $\sim 0.5 \%$. This problem can be overcome by utilizing the super-reflections and kinematically allowed diffraction reflections for maghemite. Even though magnetite and maghemite share virtually almost the same crystallographic spacings (lattice constants are $a_{\text {magn }}=8.397 \AA, a_{\text {magh }}=8.351 \AA$ ), the broken symmetry along the $c$-axis of maghemite, i.e., $c=3 a$, provides unique characteristic super-reflections and kinematically allowed reflections of maghemite that are not present in magnetite diffraction patterns. As shown in Fig. 5b, the low index lattice spacings corresponding to (110), (210), (211), and (421) atomic planes should be present in the maghemite diffraction patterns while they are forbidden in magnetite. The most intense diffraction reflections of these, thus the easier to be identified, are due to (210) and (211) planes. The difficulty in imaging diffraction patterns at these low spatial frequencies is the proximity of transmitted (000) beam. The (000) beam contains the majority of the transmitted electron intensity, as well as diffusively scattered electrons which broaden the (000) beam; as a result, the low index plane reflections usually overlap with the transmitted beam, as shown in Fig. 5a. We note that even with a beam stopper the low-angle Bragg scattered electrons will be superimposed with the spread of the (000) beam. In order to capture the low scattering vectors and separate them from the (000) beam, we used post-column electron energy filtering to reduce the background. Figure $5 c$ shows a diffraction pattern taken at a longer camera length with a 5-eV energy window centered on the zero-loss peak (ZLP) to ensure the removal of inelastic scattered electron from the diffraction pattern. The energy filtered diffraction pattern clearly shows the (111) and (220) diffraction rings corresponding to $\mathrm{Fe}_{3} \mathrm{O}_{4}$; however, the (110), (210), and (211) representing the maghemite phase are missing. In addition, if the maghemite phase was present in the NPs, the (210) and (211) Bragg reflections would have produced rings with slightly higher intensity than the (111) reflections of magnetite observed in Fig. 5c). This clearly shows that the completely oxidized NPs have a magnetite structure.

The results obtained show that annealing at higher temperature $\left(700{ }^{\circ} \mathrm{C}\right)$ under low background $\mathrm{O}$ pressure promotes the formation of single-phase magnetite nanoparticles. These findings are in stark contrast with reports of formation of NPs under higher $\mathrm{O}_{2}$ pressure which are usually core-shell 
Figure 3 Nanoparticle structure and size at $700{ }^{\circ} \mathrm{C}$; a, b Bright field image showing increased size and faceting of the nanoparticles; c selectedarea image relative to diffraction pattern $\mathbf{d}$ showing rings compatible with both $\mathrm{Fe}_{3} \mathrm{O}_{4}$ and $\gamma-\mathrm{Fe}_{2} \mathrm{O}_{3} ; \mathbf{e}, \mathbf{f}$ nanoparticle size analysis showing a $6.6 \mathrm{~nm}$ mean NP diameter (equivalent area circular diameter).

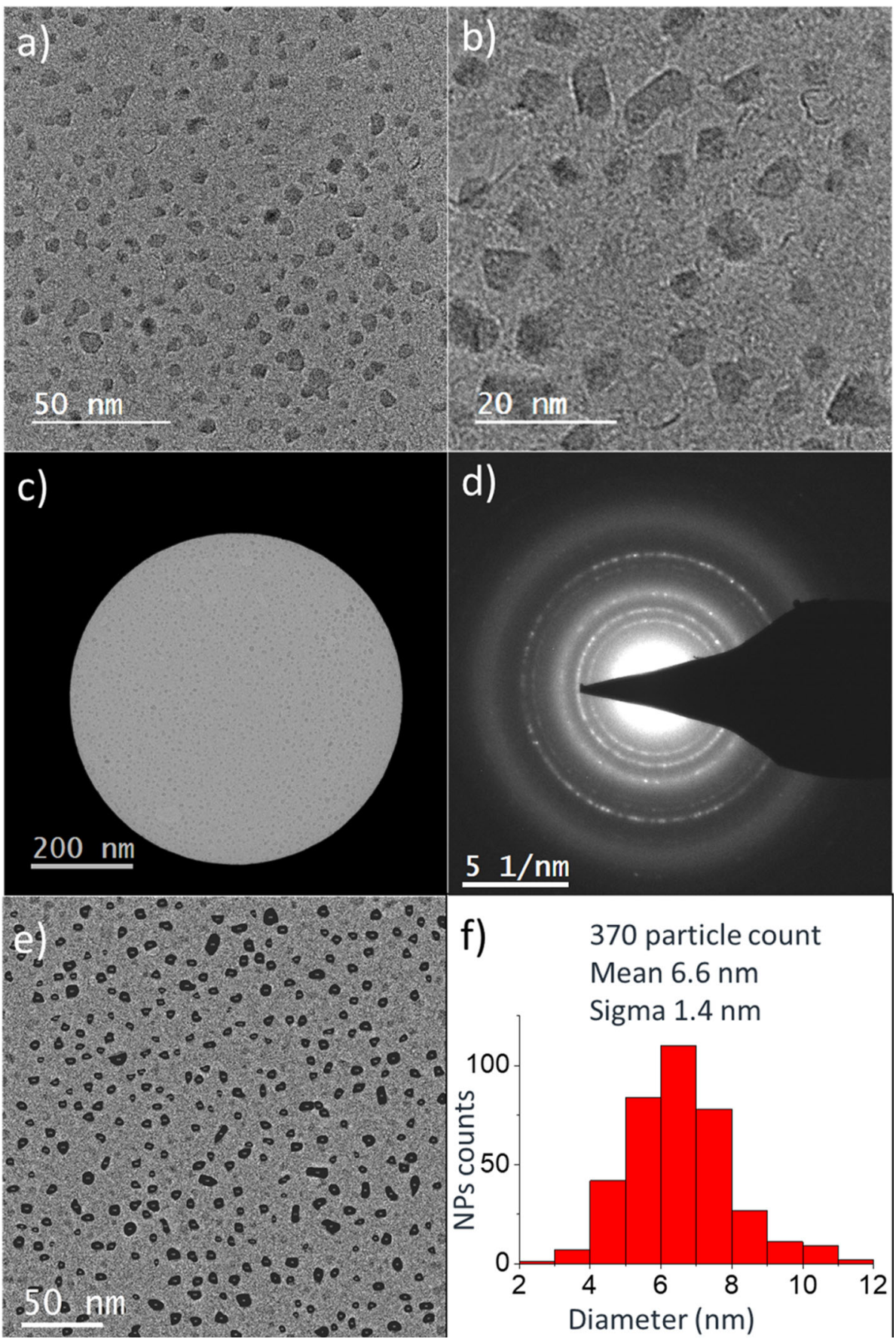

$[19,20,22]$ and have a significant number of structural defects including antidomain phase boundaries that originate at the core-shell interface, and are responsible for complex magnetic behaviors of the nanoparticles. It is interesting also to note that according to the calculated structural phase stability for iron oxides with respect to temperature and $\mathrm{O}_{2}$ pressure [37] for bulk systems, at both $600{ }^{\circ} \mathrm{C}$ and $700{ }^{\circ} \mathrm{C}$ and at $\mathrm{O}_{2}$ pressure of $10^{-4} \mathrm{~Pa}$, only the $\alpha-\mathrm{Fe}_{2} \mathrm{O}_{3}$ phase is energetically favorable, while the $\mathrm{Fe}_{3} \mathrm{O}_{4}$ phase is expected above $800{ }^{\circ} \mathrm{C}$. These calculations do not correspond to NPs; our observations clearly show that, at the nanoscale, the transformation into $\mathrm{Fe}_{3} \mathrm{O}_{4}$ happens at lower temperature $\left(700{ }^{\circ} \mathrm{C}\right)$, and it is preceded not from $\alpha-\mathrm{Fe}_{2} \mathrm{O}_{3} \mathrm{NPs}$, as discussed above. We note that the quasi-equilibrium conditions during in situ TEM annealing will also contribute to the 
Figure 4 HRTEM images of oxidized nanoparticles at $700{ }^{\circ} \mathrm{C}$ showing nanoparticles oriented along different zone axes, with clear faceting and no disorder at their surfaces. (The insets are digital diffractograms).
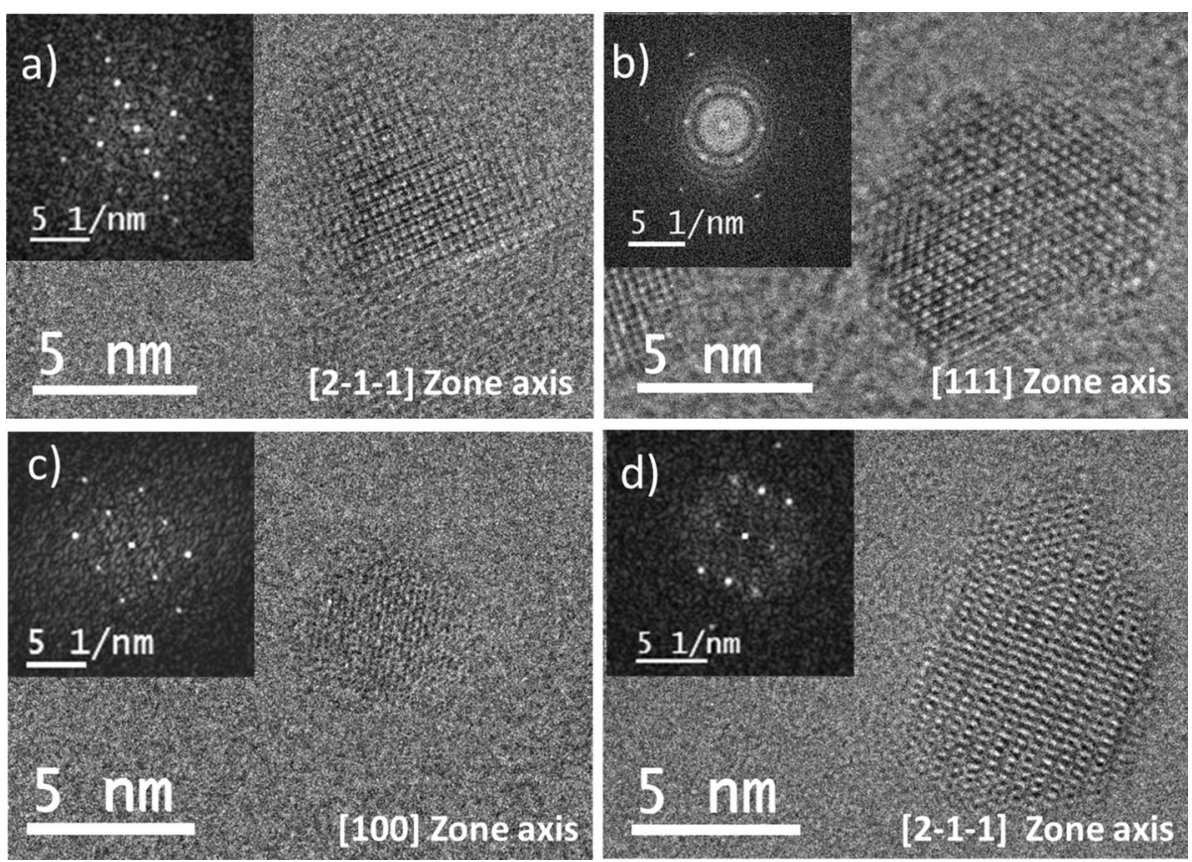


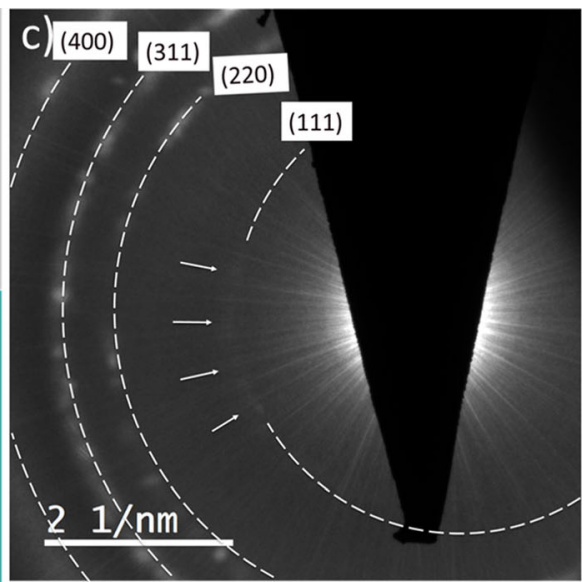

Figure 5 Analysis of diffraction pattern from nanoparticles at $700{ }^{\circ} \mathrm{C}$. a DPs superimposed with $\mathrm{Fe}_{3} \mathrm{O}_{4}$ and $\gamma-\mathrm{Fe}_{2} \mathrm{O}_{3}$ calculated for powder of $20 \mathrm{~nm} \mathrm{NPs}$; the black dashed box highlights the area where the low index diffraction rings of $\mathrm{Fe}_{3} \mathrm{O}_{4}$ and $\gamma-\mathrm{Fe}_{2} \mathrm{O}_{3}$

discrepancy between the bulk and NP behaviors besides size effects.

\section{Conclusions}

In summary, in this work we studied the evolution of sputtered amorphous $\mathrm{Fe}$ thin films deposited on amorphous $\mathrm{C}$ as a function of temperature and low (background) $\mathrm{O}_{2}$ pressure by using in situ transmission electron microscopy. We have shown that should/can appear, as outlined also by black box in b. c Energy filtered DPs, with superimposed $\mathrm{Fe}_{3} \mathrm{O}_{4}$ calculated diffraction rings (dashed white lines).

amorphous $\mathrm{Fe}$ thin films dewet with increasing temperature and spherical shape nanoparticles are formed. Continuous annealing in the presence of residual oxygen $\mathrm{O}_{2}$ under a microscope column vacuum of $4.0 \times 10^{-4} \mathrm{~Pa}$ drives the crystallization and oxidation process. The structural phases of the nanoparticles at $600{ }^{\circ} \mathrm{C}$ are with mixed phases and structure. Electron diffraction measurements show that the majority of NPs have atomic lattice spacings corresponding to $\alpha$-Fe. Further annealing to $700{ }^{\circ} \mathrm{C}$ drastically changes both the morphology and 
structure of the nanoparticles. Nanoparticle mean size increases from 5.2 to $6.6 \mathrm{~nm}$, and from spherical they became faceted. Zero-loss energy filtered electron diffraction patterns revealed that all particles transform into magnetite nanoparticles, with no trace of other Fe oxide phases or core-shell structured nanoparticles. The atomic resolution TEM imaging confirms the single-crystal structure of the magnetite nanoparticles and their structural integrity. This work demonstrates that annealing in low pressure $\mathrm{O}_{2}$ leads to creation of single-phase magnetite nanoparticles starting from amorphous Fe thin film and can provide a way to avoid core-shell or mixed Fe oxide phase nanoparticles.

\section{Acknowledgements}

Dr. L. Lari would like to thank Dr. P. Grammatikopoulos and Prof. M. Sowwan for their support during his research visit at OIST.

\section{Compliance with ethical standards}

Conflict of interest The authors declare that there is no conflict of interests regarding the publication of this article.

Open Access This article is licensed under a Creative Commons Attribution 4.0 International License, which permits use, sharing, adaptation, distribution and reproduction in any medium or format, as long as you give appropriate credit to the original author(s) and the source, provide a link to the Creative Commons licence, and indicate if changes were made. The images or other third party material in this article are included in the article's Creative Commons licence, unless indicated otherwise in a credit line to the material. If material is not included in the article's Creative Commons licence and your intended use is not permitted by statutory regulation or exceeds the permitted use, you will need to obtain permission directly from the copyright holder. To view a copy of this licence, visit http://creativecommons.org/licen ses/by $/ 4.0 /$.

\section{References}

[1] Laurent S, Forge D, Port M, Roch A, Robic C, Vander Elst L, Muller RN (2008) Magnetic iron oxide nanoparticles: synthesis, stabilization, vectorization, physicochemical characterizations, and biological applications. Chem Rev 108(6):2064-2110. https://doi.org/10.1021/cr068445e

[2] Gupta AK, Gupta M (2005) Synthesis and surface engineering of iron oxide nanoparticles for biomedical applications. Biomaterials 26(18):3995-4021. https://doi.org/10. 1016/j.biomaterials.2004.10.012

[3] Kovács A, Sato K, Lazarov VK, Galindo PL, Konno TJ, Hirotsu Y (2009) Direct Observation of a Surface Induced Disordering Process in Magnetic Nanoparticles. Phys Rev Lett 103(11):115703

[4] Liu Y, Majetich SA, Tilton RD, Sholl DS, Lowry GV (2005) TCE dechlorination rates, pathways, and efficiency of nanoscale iron particles with different properties. Environ Sci Technol 39(5):1338-1345. https://doi.org/10.1021/e s049195r

[5] Berger P, Adelman NB, Beckman KJ, Campbell DJ, Ellis AB, Lisensky GC (1999) Preparation and properties of an aqueous ferrofluid. J Chem Educ 76(7):943. https://doi.org/ 10.1021/ed076p943

[6] Pankhurst QA, Thanh NTK, Jones SK, Dobson J (2009) Progress in applications of magnetic nanoparticles in biomedicine. J Phys D Appl Phys 42(22):224001. https://doi. org/10.1088/0022-3727/42/22/224001

[7] Vernieres J, Steinhauer S, Zhao J, Chapelle A, Menini P, Dufour N, Diaz RE, Nordlund K, Djurabekova F, Grammatikopoulos P, Sowwan M (2017) Gas phase synthesis of multifunctional Fe-based nanocubes. Adv Funct Mater 27(11):1605328. https://doi.org/10.1002/adfm.201605328

[8] Steinhauer S, Vernieres J, Krainer J, Köck A, Grammatikopoulos P, Sowwan M (2017) In situ chemoresistive sensing in the environmental TEM: probing functional devices and their nanoscale morphology. Nanoscale 9(22):7380-7384. https://doi.org/10.1039/C6NR09322A

[9] Pereira C, Pereira AM, Rocha M, Freire C, Geraldes CFGC (2015) Architectured design of superparamagnetic Fe3O4 nanoparticles for application as MRI contrast agents: mastering size and magnetism for enhanced relaxivity. J Mater Chem B. https://doi.org/10.1039/C5TB00789E

[10] Li F, Li Y, Zeng XC, Chen Z (2015) Exploration of highperformance single-atom catalysts on support $\mathrm{M} 1 / \mathrm{FeOx}$ for $\mathrm{CO}$ oxidation via computational study. ACS Catal 5(2):544-552. https://doi.org/10.1021/cs501790v

[11] Qiao B, Wang A, Yang X, Allard LF, Jiang Z, Cui Y, Liu J, Li J, Zhang T (2011) Single-atom catalysis of CO oxidation using Pt1/FeOx. Nat Chem 3(8):634-641. https://doi.org/10. 1038/nchem.1095

[12] Sun X, Lin J, Zhou Y, Li L, Su Y, Wang X, Zhang T (2017) $\mathrm{FeOx}$ supported single-atom $\mathrm{Pd}$ bifunctional catalyst for 
water gas shift reaction. AIChE J 63(9):4022-4031. https://d oi.org/10.1002/aic.15759

[13] Park J, An K, Hwang Y, Park J-G, Noh H-J, Kim J-Y, Park J-H, Hwang N-M, Hyeon T (2004) Ultra-large-scale syntheses of monodisperse nanocrystals. Nat Mater 3(12):891-895.https://www.nature.com/nmat/journal/v3/n12/suppinf o/nmat1251_S1.html

[14] Yu WW, Falkner JC, Yavuz CT, Colvin VL (2004) Synthesis of monodisperse iron oxide nanocrystals by thermal decomposition of iron carboxylate salts. Chem Commun 20:2306-2307. https://doi.org/10.1039/B409601K

[15] Daou TJ, Pourroy G, Bégin-Colin S, Grenèche JM, UlhaqBouillet C, Legaré P, Bernhardt P, Leuvrey C, Rogez G (2006) Hydrothermal synthesis of monodisperse magnetite nanoparticles. Chem Mater 18(18):4399-4404. https://doi.o $\mathrm{rg} / 10.1021 / \mathrm{cm} 060805 \mathrm{r}$

[16] Teja AS, Koh P-Y (2009) Synthesis, properties, and applications of magnetic iron oxide nanoparticles. Prog Cryst Growth Charact Mater 55(1-2):22-45. https://doi.org/10.10 16/j.pcrysgrow.2008.08.003

[17] Wu W, He Q, Jiang C (2008) Magnetic iron oxide nanoparticles: synthesis and surface functionalization strategies. Nanoscale Res Lett 3(11):397-415. https://oi.or g/10.1007/s11671-008-9174-9

[18] Klacanova K, Fodran P, Simon P, Rapta P, Boca R, Jorik V, Miglierini M, Kolek E, Caplovi L (2013) Formation of $\mathrm{Fe}(0)$-nanoparticles via reduction of $\mathrm{Fe}(\mathrm{II})$ compounds by amino acids and their subsequent oxidation to iron oxides. J Chem 2013:10. https://doi.org/10.1155/2013/961629

[19] Wang CM, Baer DR, Amonette JE, Engelhard MH, Qiang Y, Antony J (2007) Morphology and oxide shell structure of iron nanoparticles grown by sputter-gas-aggregation. Nanotechnology 18(25):255603

[20] Zhao J, Baibuz E, Vernieres J, Grammatikopoulos P, Jansson V, Nagel M, Steinhauer S, Sowwan M, Kuronen A, Nordlund K, Djurabekova F (2016) Formation mechanism of Fe nanocubes by magnetron sputtering inert gas condensation. ACS Nano 10(4):4684-4694. https://doi.org/10.1021/acsna no. $6 \mathrm{~b} 01024$

[21] Martelli S, Mancini A, Giorgi R, Alexandrescu R, Cojocaru S, Crunteanu A, Voicu I, Balu M, Morjan I (2000) Production of iron-oxide nanoparticles by laser-induced pyrolysis of gaseous precursors. Appl Surf Sci 154-155:353-359. http s://doi.org/10.1016/S0169-4332(99)00385-2

[22] Pratt A, Lari L, Hovorka O, Shah A, Woffinden C, Tear SP, Binns C, Kröger R (2014) Enhanced oxidation of nanoparticles through strain-mediated ionic transport. Nat Mater 13 (1):26-30. https://doi.org/10.1038/nmat3785https:/www.nat ure.com/nmat/journal/v13/n1/abs/nmat3785.html\#suppleme ntary-information
[23] Nedelkoski Z, Kepaptsoglou D, Lari L, Wen T, Booth RA, Oberdick SD, Galindo PL, Ramasse QM, Evans RFL, Majetich S, Lazarov VK (2017) Origin of reduced magnetization and domain formation in small magnetite nanoparticles. Sci Rep 7(1):45997. https://doi.org/10.1038/sre p45997

[24] Gilks D, Lari L, Naughton J, Cespedes O, Cai Z, Gerber A, Thompson SM, Ziemer K, Lazarov VK (2013) Origin of anomalous magnetite properties in crystallographic matched heterostructures: Fe3O4(111)/MgAl2O4(111). J Phys Condens Matter 25(48):485004. https://doi.org/10.1088/0953-8 984/25/48/485004

[25] Matsuzaki K, Lazarov VK, Lari L, Hosono H, Susaki T (2012) Fe3O4(1 11 1) thin films with bulk-like properties: growth and atomic characterization. J Phys D Appl Phys 46(2):022001.https://doi.org/10.1088/0022-3727/46/2/ 022001

[26] Talbot D, Talbot J (2018) Corrosion science and technology, 3rd edn. CRC Press, Boca Raton. https://doi.org/10.1201/ 9781351259910

[27] Hussey RJ, Sproule GI, Caplan D, Graham MJ (1977) The growth and structure of oxide films formed on $\mathrm{Fe}$ in $\mathrm{O} 2$ and $\mathrm{CO} 2$ at $550^{\circ} \mathrm{C}$. Oxid Met 11(2):65-79. https://doi.org/10. 1007/bf00612135

[28] Hussey RJ, Cohen M (1971) The oxidation of Fe in the temperature range $450-550^{\circ} \mathrm{C}$ - II. The pressure range 10-3-760 torr. Corros Sci 11(10):713-721. https://doi.org/ 10.1016/S0010-938X(71)80005-7

[29] Hussey RJ, Cohen M (1971) The oxidation of $\mathrm{Fe}$ in the temperature range $450-550^{\circ} \mathrm{C}-\mathrm{I}$. The pressure range $10-6-$ 10-4 torr. Corros Sci 11(10):699-711. https://doi.org/10.1 016/S0010-938X(71)80004-5

[30] Cohen M (1959) The formation and properties of passive films on iron. Can J Chem 37(1):286-291. https://doi.org/10. 1139/v59-037

[31] Caule EJ, Cohen M (1955) The formation of thin films of iron oxide. Can J Chem 33(2):298-304. https://doi.org/10. 1139/v55-034

[32] Wriedt HA (1991) The Fe-O (iron-oxygen) system. J Ph Equilib 12(2):170-200. https://doi.org/10.1007/bf02645713

[33] Gai PL (2002) Developments in in situ environmental cell high-resolution electron microscopy and applications to catalysis. Top Catal 21(4):161-173. https://doi.org/10.1023/ A:1021333310817

[34] Steinhauer S, Wang Z, Zhou Z, Krainer J, Köck A, Nordlund K, Djurabekova F, Grammatikopoulos P, Sowwan M (2017) Probing electron beam effects with chemoresistive nanosensors during in situ environmental transmission electron microscopy. Appl Phys Lett 110(9):094103. http s://doi.org/10.1063/1.4977711 
[35] Wang CM, Baer DR, Amonette JE, Engelhard MH, Antony JJ, Qiang Y (2007) Electron beam-induced thickening of the protective oxide layer around Fe nanoparticles. Ultramicroscopy 108(1):43-51. https://doi.org/10.1016/j.ultramic.2 007.03.002

[36] Bhadeshia HKDH, Honeycombe R (2006) Steels microstructure and properties, 3rd edn. Elsevier, Amsterdam. https://doi.org/10.1016/B978-075068084-4/50002-9
[37] Lanier CH, Chiaramonti AN, Marks LD, Poeppelmeier KR (2009) The $\mathrm{Fe} 3 \mathrm{O} 4$ origin of the "Biphase" reconstruction on $\alpha$-Fe2O3(0001). Surf Sci 603(16):2574-2579. https://doi.or $\mathrm{g} / 10.1016 /$ j.susc.2009.06.006

Publisher's Note Springer Nature remains neutral with regard to jurisdictional claims in published maps and institutional affiliations. 